\title{
Steady State Two-Phase Flow Analysis of Natural Circulation in Hybrid Boiler
}

\author{
Atul M. Elgandelwar ${ }^{*}$, Radhe S. Jha², Mandar M. Lele ${ }^{3}$ \\ ${ }^{1}$ Mechanical Engineering Department, Maharashtra Institute of Technology Kothrud, Pune 411019, SPPU, India \\ ${ }^{2}$ School of Mechanical Engineering, MIT-WPU \& Head, Innovation at Heating SBU, Thermax India limited, Pune 411019, \\ India \\ ${ }^{3}$ Mechanical Engineering Department, MIT College of Engineering Kothrud, Pune 411019, SPPU, India
}

Corresponding Author Email: atulpavani@gmail.com

https://doi.org/10.18280/ijht.380421

Received: 26 August 2019

Accepted: 15 June 2020

\section{Keywords:}

natural circulation, two-phase flow, flow distribution, pressure drop, void fraction, circulation ratio, hybrid boiler

\begin{abstract}
In this present works, a generalized approach for the two-phase flow analysis of a natural circulation in hybrid boiler. The model uses the combination of node and loop equations and the Newton Raphson technique for the solution of the set of equations. Loop equations have been developed for each evaporator tube with the unique driving force and pressure drop of the concerned loop. Node equations are mainly developed for common risers and downcomers. A unique connectivity matrix has been used to correlate each branch flow with loop and node equations. The model is validated by a unique indirect method by comparing the actual water level and calculated water level. Experiments have been performed with uniform diameter of tubes in 53 channels circulating loop to find the volume of steam. The model shows good agreement with experimental investigations with a maximum of $3.57 \%$ absolute error. The model can be used for the design, analysis, and optimization of the natural circulation network.
\end{abstract}

\section{INTRODUCTION}

The hybrid boiler is the combination of a fire tube and a water tube design. Furnace and reversal chambers are of water tube design, and convective tube banks are placed in the boiler drum. Heat is generated in the furnace due to the combustion of biomass over the reciprocating grate and is partially transferred to the water wall placed around the furnace. Hot flue gas enters the convective tube bank through a reversal chamber. Furnace and reversal chambers are made of water tube design, and the evaporation of water takes place after picking the heat from the flue gas. The water and steam mixtures move upward due to the buoyancy effect and finally enter the boiler drum through the risers. Evaporator tubes receive the water from downcomers connected to the steam drum. This completes the natural circulation [1]. Industrial hybrid boiler works on the principle of natural circulation loop. Fluid flow in network developed by buoyancy forces, which is due to difference in densities. In circulation, buoyancy force is equipoised by frictional forces, losses in straight part of the risers and downcomers [2].

The design of the circulation circuit of a natural circulation boiler is extremely critical, because the heat transfer tubes must have sufficient water flow to ensure the cooling of these tubes. It becomes more critical if these heat transfer tubes are exposed to high flame temperature radiation leading to very high heat flux in a furnace section of a fired boiler. The performance of a circulation circuit is measured by circulation ratio. Circulation ratio is defined as the ratio of the mass flow rate of the steam-water mixture in the circulation loop to the steam generation rate in evaporator tubes [3]. The circulation does not provide sufficient information about the flow circulation in individual tubes, which is very important for the thermal and hydraulic performance of the boiler. The parameters that affect the distribution of the flow in the parallel channel are the header area, tube diameter, size and location of the inlet port to the header, and the direction of flow [4].

Poor distribution and a lower circulation ratio in a tube can lead to various problems, such as a departure from nucleate boiling, phase stratification, higher void fraction, and twophase flow instability. Much effort and consideration has been given to the development of a mathematical model for the flow distribution analysis for single-phase flow. Bajura and Jones [5] present a generalized model based on momentum balance for the flow distribution analysis in the flow distribution manifold. A flow distribution also poses the challenge in the design of a parallel flow heat exchanger and an iterative flow network model using a loop and node equation for the flow distribution analysis in a parallel-flow heat exchanger [6]. Ma et al. [7] proposed a generalized flow distribution model for the flow network analysis in fuel cells. Steady-state flow analysis of two-phase natural circulation is normally conducted by combining the hydraulic resistances of all parallel channels with similar height. Two-phase flow distribution is very critical in the design and analysis of a supercritical boiler. A two-phase flow distribution model is proposed using a simplified parallel flow network approach [8]. Ablanque et al. [9] present a model for two-phase flow distribution in multiple parallel tubes. Two-phase flow distribution analysis in a natural circulation boiler has different challenges, because it has different resistance and driving forces for each loop. The driving force for different loops can be different due to different height and dryness fraction, and dryness fraction is the function of flow and heat transfer. This makes the whole system of equations quite complex, and the 
development of a generalized flow network model for natural circulation analysis is extremely useful for the design and analysis of a natural circulation of hybrid boiler [10].

\section{NATURAL CIRCULATION NETWORK ANALYSIS}

Because of the natural circulation circuit of boiler is quite complex the flow distribution among evaporating tubes cannot be analyzed easily. In conventional approach, an equivalent flow resistance for parallel evaporating tubes, risers and downcomer are estimated to calculate the overall flow in circulation circuit. This does not provide the sufficient information about the flow circulation in individual tubes, which is very important for the thermal and hydraulic performance of the boiler. A generalized flow network model for Two-phase flow and pressure drop issues in network systems are solved by applied mathematics and computer software. However, due to lack of experimental results this cannot be validated. Hence developed the analytical model using unique strategy for the estimation of two-phase flow distribution and pressure drop and verified with experimental results.

\subsection{Natural circulation analysis with single loop}

Figure 1 gives a schematic diagram of single tube loop natural circulation. At the riser, the fluid absorbs heat which becomes lighter and rises. The density of water in the downcomer column is higher than the density of water and steam mixture of the riser column. The difference of pressure in these two columns causes a driving force for natural circulation. The driving force is the pressure difference of the downcomer and riser column and can be calculated as follows.

$$
\Delta P=\left(\rho_{d}-\rho_{r}\right) g H
$$

where,

$H$ is the height of the column and $g$ is the gravitational acceleration.

$\rho_{d}$ and $\rho_{r}$ are the fluid density in the downcomer and riser column and are calculated by following equations.

$$
\rho_{d}=\frac{1}{v_{f}}
$$

where, $v_{f}$ is specific volume of fluid.

$$
\rho_{r}=\frac{1}{(1-x) v_{l}-x v_{v}}
$$

where, $x$ is the dryness fraction and $v_{l}$ and $v_{v}$ are the specific volume of saturated liquid and saturated vapour.

Dryness fraction is the function of rate of heat transfer and mass flow and can be calculated by the following equation.

$$
x=\frac{Q}{q h_{f g}}
$$

where, $h_{f g}$ is the latent heat and $Q$ and $q$ are the rate of heat transfer and mass flow.

Pressure drop in circulation loop is overcome by the driving force calculated by using Eq. (1). The circulation loop consists of downcomer and riser. Downcomer pressure drop can be calculated by the following equation.

$$
\Delta \mathrm{p}_{\mathrm{d}}=\Delta \mathrm{p}_{\mathrm{df}}+\Delta \mathrm{p}_{\mathrm{dd}}
$$

where, $\Delta p_{d}$ is total pressure drop of downcomer.

$\Delta p_{d f}$ and $\Delta p_{d d}$ are frictional and dynamic pressure drop of downcomer.

$$
\begin{gathered}
\Delta P_{d f}=\frac{\rho f L v^{2}}{2 D} \\
\Delta P_{d d}=K\left(\frac{1}{2} \rho v^{2}\right)
\end{gathered}
$$

where, $\rho$ is density, $f$ is friction factor, $L$ is the length of downcomer, $v$ is the velocity, $K$ is a dynamic coefficient and $D$ is the internal diameter of the downcomer.

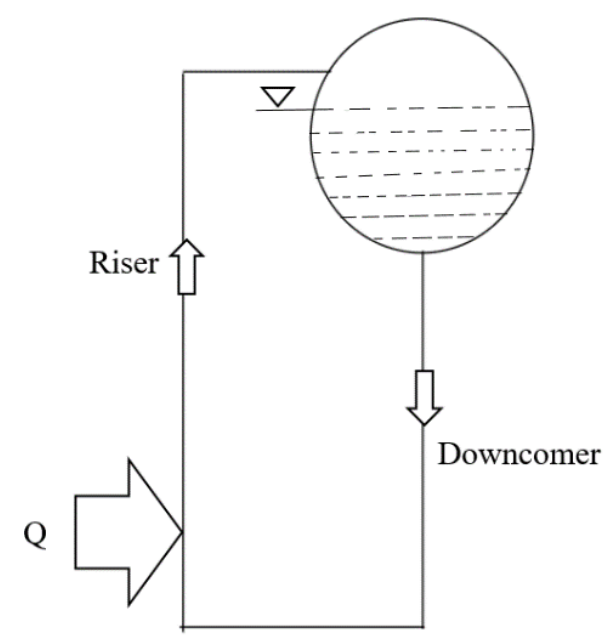

Figure 1. Single tube loop natural circulation

Flow-through the riser are two-phase and it requires a different approach for the calculation of pressure drops. Lockhart- Martinelli method is a popular method for the calculation of a two-phase pressure drop, where pressure drop is calculated by considering single-phase and corrected by applying Lockhart-Martinelli multiplier.

Single-phase pressure drop-in the riser is calculated by considering the liquid phase and the following equation is used for the calculation of pressure drop [11].

$$
\Delta P_{r}=\Delta P_{r f}+\Delta P_{r d}
$$

where, $\Delta p_{r}$ is total pressure drop of the riser.

$\Delta p_{r f}$ and $\Delta p_{r d}$ are frictional and dynamic pressure drop of the riser.

Riser pressure drop is corrected for two-phase flow by using the following equation.

$$
\Delta P_{r c}=\emptyset^{2} \Delta P_{r}
$$

where, $\Delta p_{r c}$ and $\Delta p_{r}$ are two-phase pressure drop and singlephase pressure drop.

$\emptyset^{2}$ is the two-phase multiplier and can be calculated by following equations.

$$
\emptyset^{2}=1+\frac{18}{X_{t t}}+\frac{1}{X_{t t}^{2}}
$$


where, $X_{t t}$ is the Martinelli parameter and is calculated by the following equation when both liquid and gaseous phases are in the turbulent regime.

$$
X_{t t}=\left(\frac{1-x}{x}\right)^{0.9}\left(\frac{\rho_{G}}{\rho_{L}}\right)^{0.5}\left(\frac{\mu_{L}}{\mu_{G}}\right)^{0.1}
$$

where, $x$ is the dryness fraction and $\rho$ and $\mu$ are density and viscosity of liquid and gas phase.

As the driving head overcome the frictional and dynamic resistance of the circulation loop consisting of downcomer and riser, following equation used to calculate the mass flow rate of the circulation loop [12]

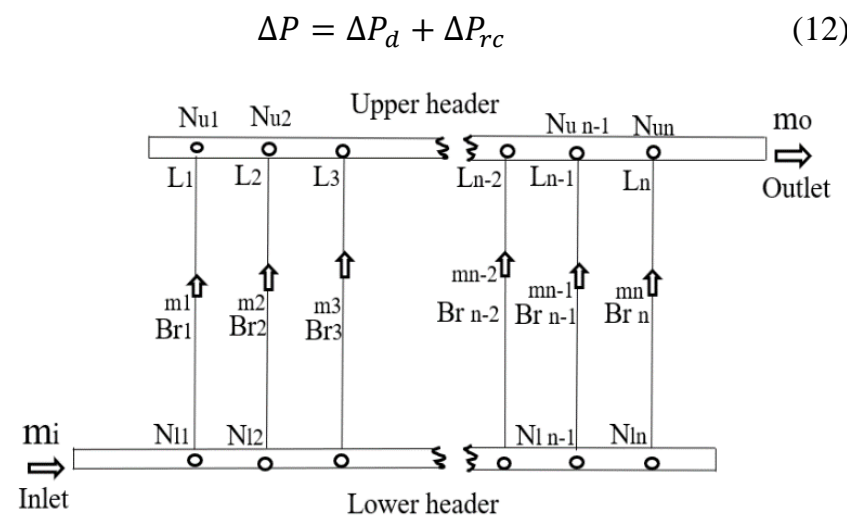

Figure 2. Flow network

\subsection{Generalize mathematical model for multiple loop}

Flow network modeling is used to analyze the flow distribution in a complex flow network problem (Figure 2). A typical flow network includes a complex network of interconnecting pipes connected with the manifolds. A complex flow network problem is solved by using Kirchhoff's analogy, where flow and pressure are treated respectively as current and potential of an electric circuit [13]. In this method, the flow network problem is resolved in a set of nodes and loop equations, as follows:

1. Node Equation-This equation represents flow balance on a node, where the incoming flow is equated with the outgoing flow.

2. Loop Equation-In this equation, an algebraic summation pressure drop of a loop is equated with zero.

The flow network model can be extended for two-phase flow and exploited for circulation analysis of a natural circulation boiler. Figure 3 shows a typical natural circulation network with a downcomer, downcomer header, riser tubes, and riser header connected to the steam drum. It has $\mathrm{N}$ riser tubes, which divide downcomer and riser headers in the $\mathrm{N}$ section. All of these sections can be treated as the branches of the circulation loop [14]. The downcomer receives saturated water from the steam drum, which is distributed among riser tubes through downcomer headers and finally collected in riser headers before entering the steam drum and completing the circulation loop. The flow path from downcomer to steam drum through each riser tube can be treated as an independent loop. A typical loop includes a downcomer, some branches of the downcomer header, a riser tube, and some section of the riser header. This circulation network has $3 \mathrm{~N}$ branches, $2 \mathrm{~N}$ nodes, and $\mathrm{N}$ loops. The $2 \mathrm{~N}$ node equations and $\mathrm{N}$ loop equations can be generated to solve this network problem for computation, and the $3 \mathrm{~N}$ branches' flows are the unknowns of these sets of simultaneous equations. A generalized circulation network model can be developed for a circulation network of 1 number of branches, $m$ number of nodes, and n number of loops.

The node equation specifies that the summation of net flow at any node is zero and can be expressed as follows:

A generalized circulation network model can be developed for a circulation network of 1 number of branches, $m$ number of nodes and $\mathrm{n}$ number of loops.

Node equation specifies that the summation of net flow at any node is zero and can be expressed by the following equations.

$$
\sum_{j=1}^{l} T_{i j} q_{j}=0(i=1,2,3, \ldots, m)
$$

where,

$\mathrm{T}_{\mathrm{ij}}$ - Flow direction of $\mathrm{j}_{\text {th }}$ branch with relative to $\mathrm{i}_{\text {th }}$ node

$\mathrm{q}_{\mathrm{j}}$ - Mass flow rate through $\mathrm{j}_{\mathrm{th}}$ branch

The sign convention used for $T_{i j}$ is as shown below:

$$
=\left\{\begin{array}{c}
+1, \text { if flow reaching a node } \\
0, \text { if no connection between branch } \mathrm{i} \text { and node } \mathrm{j} \\
-1, \text { if flow leaving the node }
\end{array}\right.
$$

Loop equation states that the sum of pressure loss across a loop should be zero and can be expressed by the following equation.

$$
\sum_{\mathrm{j}=1}^{\mathrm{l}} \mathrm{M}_{\mathrm{ij}} \Delta \mathrm{P}_{\mathrm{cj}}-\Delta P_{i}=0(\mathrm{i}=1,2, \ldots, \mathrm{n})
$$

where,

$M_{i j}$-flow direction in $\mathrm{j}_{\text {th }}$ branch with relative to $\mathrm{i}_{\text {th }}$ loop

$\Delta p_{c j}$ represents two-phase pressure drop in $j_{\text {th }}$ branch and calculated by adding frictional and dynamic pressure drop and multiplying by two phase multiplier explained in single loop natural circulation problem. $\Delta P_{i}$ represents the driving head for $\mathrm{i}_{\text {th }}$ loop and calculated the method as explained in the single loop natural circulation problem.

The sign convention used for $M_{i j}$ is as shown below: -

$$
M_{i j}=\left\{\begin{array}{cc}
+1, & \text { if fluid flow in similar direction } \\
0, & \text { if brach does not belong to loop } \\
-1, & \text { if fluid flow is opposite in the } \\
& \text { direction to show in direction }
\end{array}\right.
$$

In the circulation network model, $l$ branches, $m$ nodes and $n$ loops have been considered. Loop and node equations are carefully selected to cover all branches. $l$ is the number of branches and branch represents the number of unknowns, $m$ and $\mathrm{n}$ are the number of nodes and loops and provides a number of the equation. it must satisfy the following condition.

$$
l=m+n
$$

A set of $m+n$ node and loop equations are solved to estimate the flow through each branch. This can be solved by the Newton Raphson technique. In the Newton Raphson technique, $(m+n)$ functions represent the $(m+n)$ equations. The function for node equations is represented as follows.

$$
f_{i}-\sum_{\mathrm{j}=1}^{\mathrm{l}} \mathrm{T}_{\mathrm{ij}} \mathrm{q}_{\mathrm{j}}=0 \quad(\mathrm{i}=1,2,3, \ldots, m)
$$




$$
f_{m+i}-\left(\sum_{\mathrm{j}=1}^{\mathrm{l}} \mathrm{M}_{\mathrm{ij}} \Delta \mathrm{P}_{\mathrm{cj}}-\Delta P_{i}\right)=0 \quad(\mathrm{i}=1,2,3, \ldots, n)
$$

Eq. (19) represents functions for the loop equation.

\section{SOLUTION STRATEGY}

$(m+n)$ functions represent the all concerned node and loop equations. These equations are solved by the Newton Raphson technique. Initial flow is assumed for each branch to calculated other dependent parameters and functions. Following $(m+n)$ linear equations are simultaneously solved to calculate all required flow corrections.

$$
\left\{\begin{array}{cccccc}
\frac{\partial f_{1}}{\partial q_{1}} & \frac{\partial f_{1}}{\partial q_{2}} & - & - & - & \frac{\partial f_{1}}{\partial q_{m+n}} \\
\frac{\partial f_{2}}{\partial q_{1}} & \frac{\partial f_{2}}{\partial q_{2}} & - & - & - & \frac{\partial f_{2}}{\partial q_{m+n}} \\
\mid & \mid & \mid & \mid & \mid & \mid \\
\mid & \mid & \mid & \mid & \mid & \mid \\
\mid & \mid & \mid & \mid & \mid & \mid \\
\frac{\partial f_{m+n}}{\partial q_{1}} & \frac{\partial f_{m+n}}{\partial q_{2}} & - & - & - & \frac{\partial f_{m+n}}{\partial q_{m+n}}
\end{array}\right\}\left\{\begin{array}{c}
\Delta q_{i} \\
\Delta q_{2} \\
\mid \\
\mid \\
\mid \\
\Delta q_{m+n}
\end{array}\right\}=\left\{\begin{array}{c}
-f_{1} \\
-f_{2} \\
\mid \\
\mid \\
\mid \\
-f_{m+n}
\end{array}\right\}
$$

$$
\begin{aligned}
& \left\{\begin{array}{c}
\left\{q_{i}\right. \\
\Delta q_{2} \\
\mid \\
\mid \\
\Delta q_{m+n}
\end{array}\right\} \\
& =\left\{\begin{array}{cccccc}
\frac{\partial f_{1}}{\partial q_{1}} & \frac{\partial f_{1}}{\partial q_{2}} & - & - & - & \frac{\partial f_{1}}{\partial q_{m+n}} \\
\frac{\partial f_{2}}{\partial q_{1}} & \frac{\partial f_{2}}{\partial q_{2}} & - & - & - & \frac{\partial f_{2}}{\partial q_{m+n}} \\
\mid & \mid & \mid & \mid & \mid \\
\mid & \mid & \mid & \mid & \mid \\
\mid & \mid & \mid & \mid & \mid \\
\frac{\partial f_{m+n}}{\partial q_{1}} & \frac{\partial f_{m+n}}{\partial q_{2}} & - & - & - & \frac{\partial f_{m+n}}{\partial q_{m+n}}
\end{array}\right\}^{-1} \quad\left\{\begin{array}{c}
-f_{1} \\
-f_{2} \\
\mid \\
\mid \\
\mid \\
-f_{m+n}
\end{array}\right\}
\end{aligned}
$$

For the convergence criterion the iterative calculations are done using Visual Basic code which runs in Excel. The minimum residual for the mass flow rate in individual tube in natural circulation boiler is calculated. Additionally, before stopping the iterative calculations, it is ensured that the difference in mass flow rates between the initial and the final of the absolute value is less than $0.001 \%$.

Flow corrections are implemented to calculate the new set of flow for all branches and iteration is repeated till the convergence criteria is not satisfied.

\section{EXPERIMENTAL INVESTIGATIONS}

\subsection{Geometrical description}

Figure 3 shows a schematic of a hybrid boiler with a reciprocating grate combustor. A natural circulation network consists of downcomers to carry the drum water to evaporator tubes and risers to carry the water-steam mixture to the steam drum. The furnace is surrounded by water tube panel, where the majority of heat transfer takes place due to radiation. Relatively cooled flue gas enters in the set of convective tubes surrounded by drum water, where mainly heat is being transferred due to convection. Evaporation takes place in water tube panel and convective tube bank.

Due to symmetry, one half of the circuit has been taken for the analysis. Figure 4 shows a flow diagram of the boiler, used to test and validate the model performance. In network numbered and defined the branches and nodes. The length and diameter data of tubes, risers and downcomers are included in the Table 1.

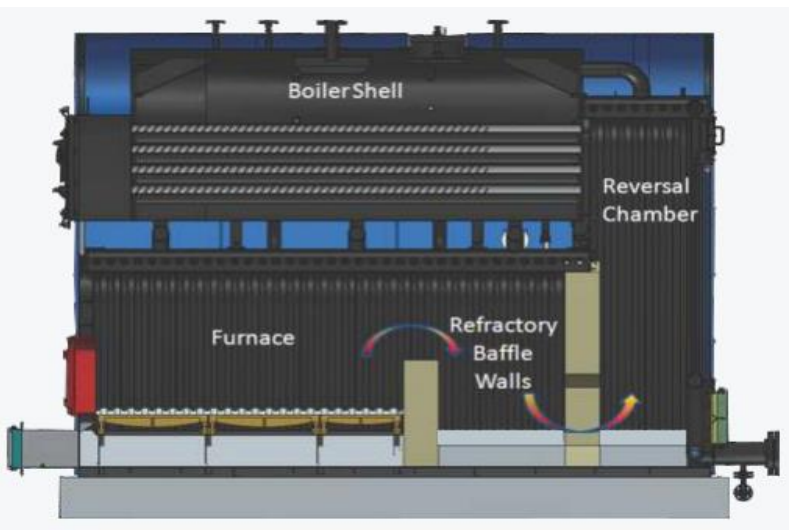

Figure 3. Schematic diagram of a hybrid boiler

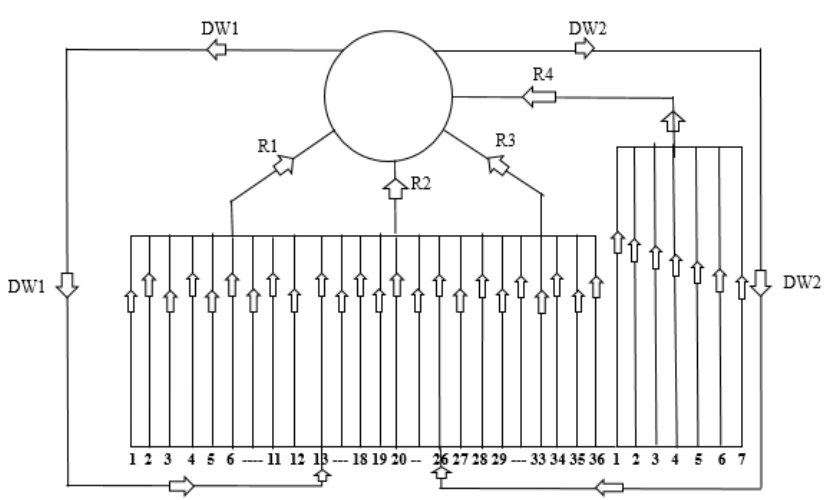

Figure 4. Flow diagram of a hybrid boiler

Table 1. Design parameters of the circulation network of a Hybrid boiler

\begin{tabular}{cccccc}
\hline \multirow{2}{*}{ Sr. No. } & \multirow{2}{*}{ Description } & \multicolumn{3}{c}{ Dimensions are in mm } & \multirow{2}{*}{ Quantity } \\
\cline { 3 - 5 } & O.D. & Thickness & Length & \\
\hline 1 & Bottom Header Dimension & 168.3 & 10.97 & 4300 & 1 \\
3 & Top Header Dimension-1 & 168.3 & 10.97 & 3326.5 & 1 \\
3 & Top Header Dimension-2 & 168.3 & 10.97 & 821 & 1 \\
4 & Number of tubes & 50.8 & 3.25 & 1705 & 72 \\
5 & Number of tubes & 50.8 & 3.25 & 2817 & 14 \\
6 & Number of tubes & 50.8 & 3.25 & 1900 & 7 \\
7 & Downcomers & 88.9 & 11.13 & 2191 & 4 \\
8 & Risers & 114.3 & 11.13 & 669 & 6 \\
9 & Riser & 114.3 & 11.13 & 161 & 1 \\
10 & Boiler drum & 3896 & 14 & 2500 & 1 \\
\hline
\end{tabular}


As the circulation circuit of boiler is quite complex the flow distribution among evaporating tubes cannot be analyzed easily. In conventional approach, an equivalent flow resistance for parallel evaporating tubes, risers and downcomer are estimated to calculate the overall flow in circulation circuit. This provides the sufficient information about the flow circulation in individual tubes, which is very important for the thermal and hydraulic performance of the boiler.

\subsection{Model validation}

A boiler of $2 \mathrm{TPH}$ capacity is selected for testing and validation of the generalized circulation model. Figure 4 shows the circulation flow diagram of the water tube furnace of the boiler. Due to symmetry, one half of the circuit has been taken for the analysis. The length and diameter of all tubes, headers, risers and downcomers are given in Table 1.

Circulation network includes the drum with 7 risers, 4 downcomers and 93 evaporating tubes, which are placed in lower and upper manifolds. The dimensional details of the circulation circuit are listed in Table 1.

Water tube furnace is split into two sections with different height. A tall furnace section is placed after combustion for the flow reversal. These furnace sections are surrounded by water tube panel. In a generalized natural circulation model, heat transfer is given as an input to the model. Heat transfer in the furnace is calculated as a function of pressure and fuel firing rate by using a stirred reactor model. The first section is placed over the firing zone and luminous radiation is assumed for the furnace analysis.

The second section is placed after combustion for the flow reversal and nonluminous radiation is assumed for the calculation of heat transfer. These heat transfers are equally distributed among the tubes in the respective sections.

Figure 5 shows the dryness fraction in the various tubes in both the firing section and flow reversal section of the furnace [15]. This figure captures the variation in dryness fraction among the tubes due to poor flow distribution. It is difficult to measure the flow and dryness fraction of these tubes to validate the model $[16,17]$. A novel method of validation strategy is used. The method involves the measurement of water level as a function of pressure during the boiler startup. As steam is not consumed during the boiler startup, the change in void fraction is primarily responsible for the increase in water level. The dryness fraction of each tube is calculated by using the generalized circulation model [18].

This calculated dryness fraction is used for the calculation of the void fraction of each tube and its effect on the steam volume below the water level. Void fraction $(\alpha)$ can be calculated by Smith's correlation [19].

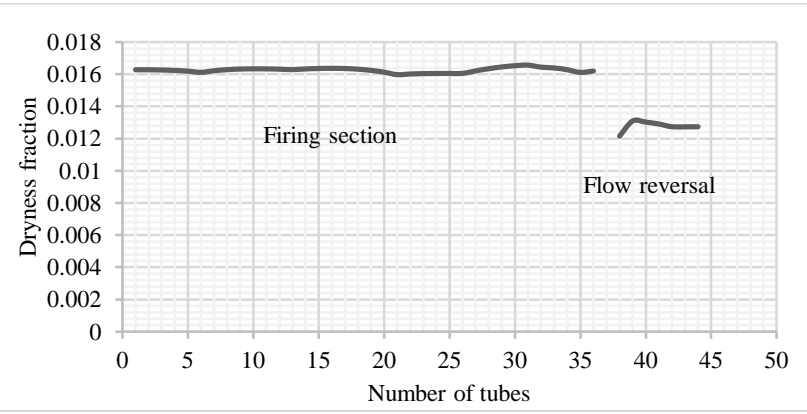

Figure 5. Dryness fraction in the furnace section

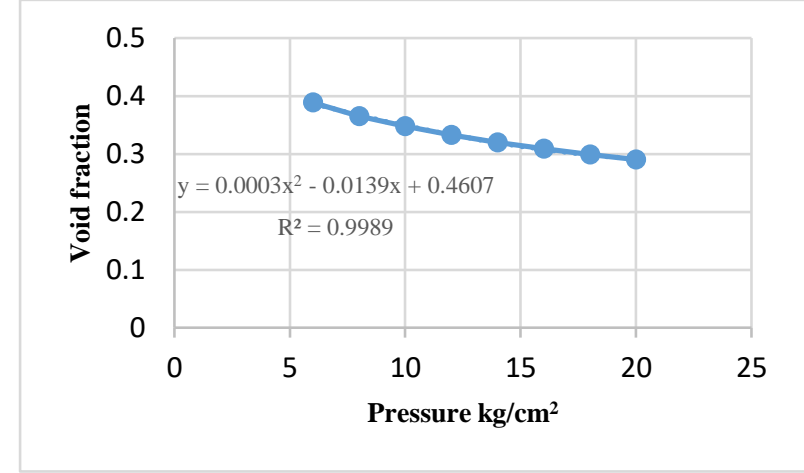

Figure 6. Void fraction as function of pressure

Circulation analysis is conducted at full load conditions for different steam pressure. Figure 6 shows the variation of the void fraction at different steam pressures.

The change in the void fraction is responsible for the change in water level, as it changes the steam volume below the water level. The steam volume below the water level is deduced by using void fraction and volume of the riser tube by using the following equation.

$$
V_{s}=\alpha V_{r}
$$

where, $V_{s}$ and $V_{r}$ are steam volume below water level and riser volume.

Experimental measurements were performed on ComBloc multi-fuel boiler at Thermax limited Pune to measure the pressure in $\mathrm{kg} / \mathrm{cm}^{2}$ and boiler drum level in litres. The Figure 7 shows the boiler shell geometry with input data of boiler shell in Table 2.

Boiler is fired at full load condition and pressure and water level are noted. The steam volume below the water level is calculated from the measured water level and the initial water volume. The calculated steam volume from circulation analysis is compared with the steam volume deduced from the measured water level [20].

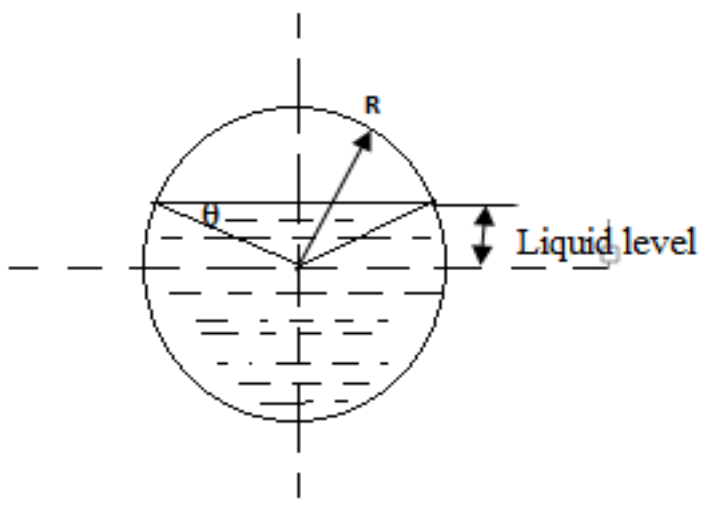

Figure 7. Boiler shell geometry

Table 2. The following data shows the input data of boiler

\begin{tabular}{cc}
\hline Drum radius & $0.613 \mathrm{~m}$ \\
\hline Height & $0.1 \mathrm{~m}$ \\
\hline No. of tubes & 83 \\
\hline Tube OD & $0.0635 \mathrm{~m}$ \\
\hline Length of drum & $3 \mathrm{~m}$ \\
\hline
\end{tabular}




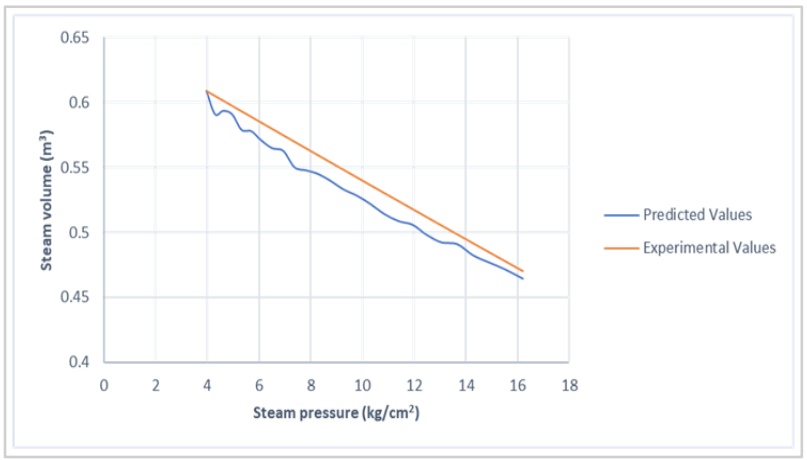

Figure 8. Comparison between experimental and analytical result of steam volume

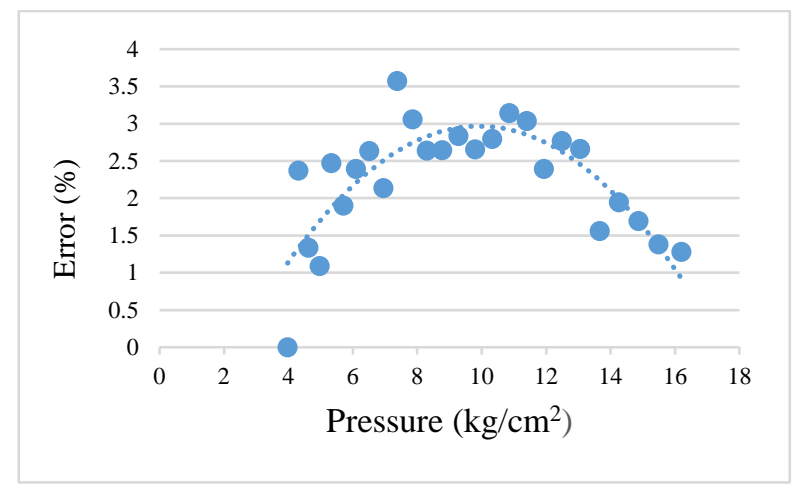

Figure 9. Error analysis of steam volume values

Figure 8 shows the steam volume derived from the circulation model and experimental analysis. Results are compared and absolute errors are plotted as a function of pressure in Figure 9.

At $100 \%$ load condition for various pressure range, the analytical and experimental steam volume values come out approximately same and which shown good qualitative agreement between analytical results and experimental results.

\section{RESULTS AND DISCUSSION}

A generalized flow network model for two-phase natural circulation analysis estimates the flow distribution and dryness fraction in the various evaporating tubes. Figure 5 shows the dryness fraction of the various evaporator tubes in a natural circulation boiler. The total flow through the natural circulation circuit is estimated, and the circulation ratio is studied for different pressure and load conditions.

Presented results show the circulation ratio and void fraction parameters in the evaporating tubes for the whole range of designed operating conditions from $30 \%$ to $100 \%$ of the nominal full load.

\subsection{Effect of load on the circulation ratio}

Figure 10 shows the effect of load on the circulation ratio. It is observed that the circulation ratio decreases with increase in the load. It can be primarily attributed to the increase in the rate of combustion and heat transfer results in higher dryness fraction and hydraulic resistance. An increase in dryness fraction also results in higher driving force but the effect of increase of dryness fraction on hydraulic resistance dominates over the effect of increase in the driving force.

\subsection{Effect of Pressure on the circulation ratio}

Figure 11 shows the effect of pressure on the circulation ratio. It is observed that the circulation ratio decreases with increase in the pressure. It can be primarily attributed to the decrease in a specific volume of steam with an increase in pressure. The decrease in a specific volume of steam with an increase in pressure increases the density of evaporator tubes and riser column. This causes a reduction in driving force and subsequent reduction in flow rate.

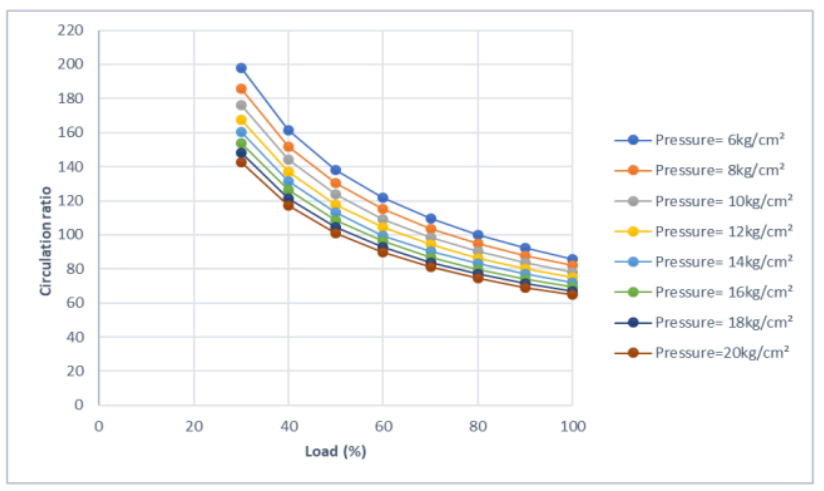

Figure 10. Circulation ratio with different load

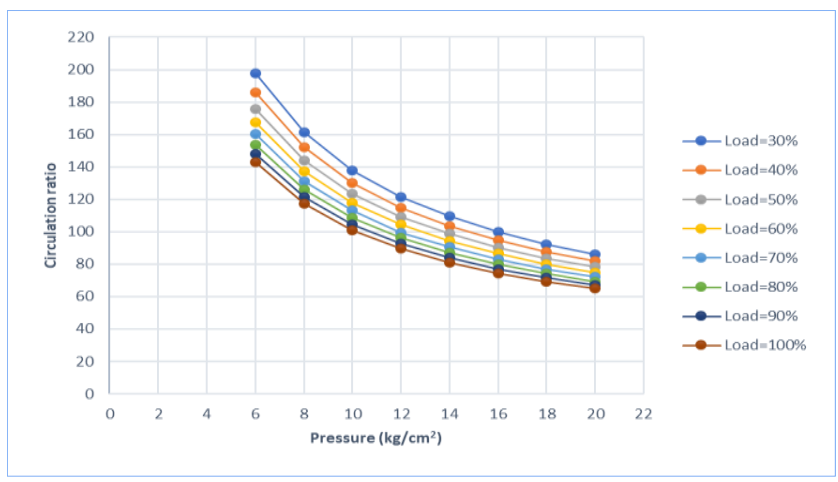

Figure 11. Circulation ratio with different pressure

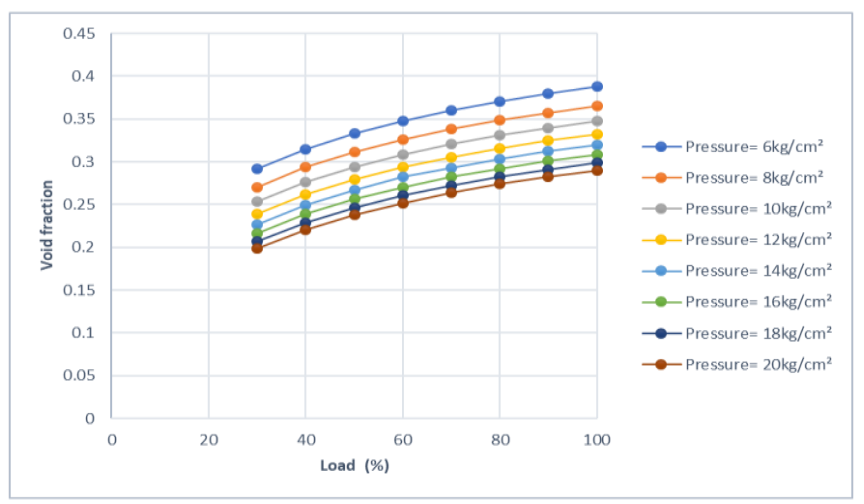

Figure 12. Void fraction with different load

\subsection{Effect of load on the void fraction}

Void fraction is a very important parameter for the hydraulic design of a natural circulation boiler. Figure 12 shows the effect of load on the void fraction. It is observed that the void fraction increases with increase in the load. It can be primarily attributed to decrease circulation and increase in dryness fraction. 


\subsection{Effect of pressure on the void fraction}

Figure 13 shows the effect of pressure on the void fraction. It is observed that the void fraction decreases with increase in the pressure. Void fraction is the primary function of dryness fraction and specific volume. It increases with increase in dryness fraction and specific volume. An increase in pressure leads to a decrease in circulation ratio and increase in dryness fraction. Due to this effect void fraction can increase but increase in specific volume dominates over this effect and void fraction decreases with increase in pressure.

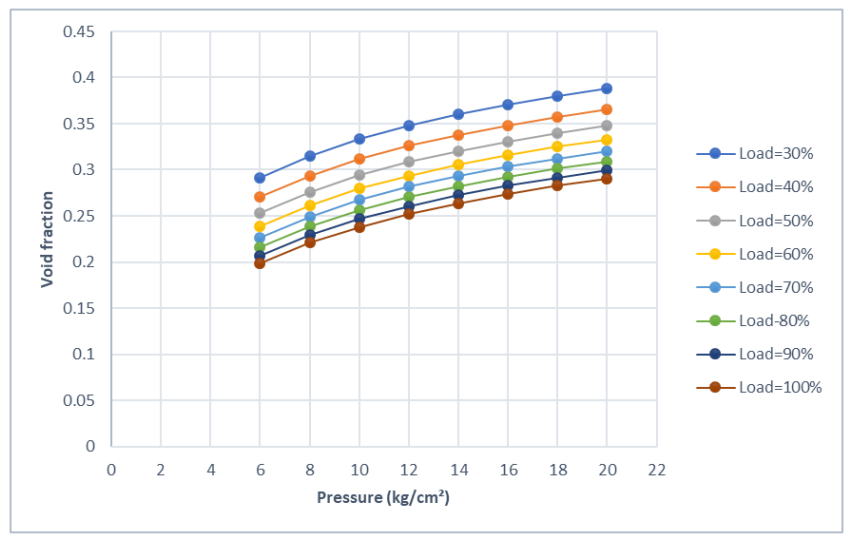

Figure 13. Void fraction with different pressure

\section{CONCLUSIONS}

In this works, 53 channels network model for natural circulation of hybrid boiler analysis is presented to calculate the two-phase flow distribution among the evaporator tubes. This model developed using the combined effect of pressure and heat load conditions. The relevant physical phenomenon was accounted for nonlinear approach and two-phase flow in various channels. The model is validated by using a unique indirect method, where the boiler is fired and pressure is raised without consuming the steam. Void fraction and its impact on water level is calculated and compared with actual water level. The model shows good agreement with the experimental results with a maximum error of $3.57 \%$. The two-phase flow distribution model is extremely useful in identifying the critical evaporator tubes with higher dryness fraction or less flow. This model can be used to predict the different failure modes like a departure from nucleate boiling, higher void fraction, phase stratification and two-phase flow instability in critical evaporator tubes and optimize the flow network design to safeguard tube from different failure modes.

The study can be used to deduce the design criteria for the design of natural circulation circuit of the hybrid boiler. The most important design aspect of the natural circulation circuit is to ensure a sufficient mass flux of circulating water to avoid burnout of evaporator tubes.

\section{ACKNOWLEDGEMENTS}

The authors thank Thermax Limited, Pune, India, for the ability to conduct experimentation and for providing design data for analysis.

\section{REFERENCES}

[1] Nayak, A.K., Vijayan, P.K. (2008). Flow instabilities in boiling two-phase natural circulation systems- a review. Science and Technology of Nuclear Installations, 2008: 5-9. https://doi.org/10.1155/2008/573192

[2] Bhusare, V.H., Bagul, R.K., Joshi, J.B., Nayak, A.K., Kannan, U., Pilkhwal, D.S., Vijayan, P.K. (2016). Steady-state flow analysis of two-phase natural circulation in multiple parallel channel loop. Nuclear Engineering and Design, 305: 706-716. https://doi.org/10.1016/j.nucengdes.2016.06.026

[3] Elgandelwar, A.M., Jha, R.S., Lele, M.M. (2020). Study of circulation ratio for natural circulation in water-tube boiler at different operating conditions. Journal of Physics: Conference Series, 1473: 1-9. https://doi.org/10.1088/1742-6596/1473/1/012026

[4] Wang, C.C., Yang, K.S., Tsai, J.S., Chen, I.Y. (2011). Characteristics of flow-distribution in compact parallel flow heat exchangers, part I: Typical inlet header. Applied Thermal Engineering, 31(16): 3226-3234. https://doi.org/10.1016/j.applthermaleng.2011.06.004

[5] Bajura, R.A., Jones, E.H. (1976). Flow distribution manifolds. Journal of Fluids Engineering, 98(4): 654-665. https://doi.org/10.1115/1.3448441

[6] Camilleri, R., Howey, D.A., McCulloch, M.D. (2015). Predicting the flow-distribution in compact parallel flow heat exchangers. Applied Thermal Engineering, 90: 551558.

https://doi.org/10.1016/j.applthermaleng.2015.07.002

[7] Ma, Z., Jeter, S.M., Abdel-Khalik, S.I. (2002). Flow network analysis application in fuel cells. Journal of Power Sources, 108(1-2): 106-112. https://doi.org/10.1016/S0378-7753(02)00008-3

[8] Pan, J., Wu, G., Yang, D. (2015). Thermal-hydraulic calculation and analysis on water wall system of 600 MW supercritical CFB boiler. Applied Thermal Engineering, 82: 225-236. https://doi.org/10.1016/j.applthermaleng.2015.03.004

[9] Ablanque, N., Oliet, C., Rigola, J., Pérez-Segarra, C.D., Oliva, A. (2015). Two-phase flow distribution in multiple parallel tubes. International Journal of Thermal Sciences, $49(6)$ : 909-921. https://doi.org/10.1016/j.ijthermalsci.2009.11.005

[10] Elgandelwar, A.M., Jha, R.S., Lele, M.M. (2020). Steady-state flow distribution analysis of natural circulation in water tube boiler. Computational Thermal Sciences, $\quad$ 12(3): 275-288. https://doi.org/10.1615/ComputThermalScien.20200339 63

[11] Grądziel, S., Majewski, K. (2019). Calculations of the pressure drop in the natural circulation boiler evaporator. MATEC Web of Conferences, 240. https://doi.org/10.1051/matecconf/201824005009

[12] Grądziel, S. (2019). Analysis of thermal and flow phenomena in natural circulation boiler evaporator. Energy, $\quad 172$ : https://doi.org/10.1016/j.energy.2019.02.003

[13] Ngoma, G.D., Godard, F. (2005). Flow distribution in an eight level channel system. Applied Thermal Engineering, 25(5-6): 831-849. https://doi.org/10.1016/j.applthermaleng.2004.06.020 
[14] Brkic, D., Praks, P. (2019). An efficient iterative method for looped pipe hydraulic free of flow correction. Fluids, 4(2): 73. https://doi.org/10.3390/fluids4020073

[15] Bhambare, K.S., Mitra, S.K., Gaitonde, U.N. (2007). Modeling of a coal-fired natural circulation boiler. Journal of Energy Resourses Technology, 129(2): 159167. https://doi.org/10.1115/1.2719209

[16] Lakshmanan, S.P., Pandey, M. (2010). Numerical investigation of startup instabilities in parallel-channel natural circulation boiling systems. Science and Technology of Nuclear Installations, 2010: 1-8. https://doi.org/10.1155/2010/574195

[17] Pleshanov, K.A., Khlyst, E.G., Zaichenko, M.N., Sterkhov, K.V. (2017). Design of a natural circulation circuit for $85 \mathrm{MW}$ steam boiler. Thermal Science, 21(3): 1503-1513. https://doi.org/10.2298/TSCI161005320P

[18] Kim, H., Chios, S. (2005). A model on water level dynamic in natural circulation drum type boiler. International Communication in Heat and Mass Transfer, 32(6):

786-796. https://doi.org/10.1016/j.icheatmasstransfer.2004.10.01 0

[19] Smith, S.L. (1969). Void Fractions in two-phase flow: A correlation based upon an equal velocity head model. Proceedings of the Institution of Mechanical Engineers, 184(1):

647-664. https://doi.org/10.1243/PIME_PROC_1969_184_051_0 2

[20] Astrom, K.J., Bell, R.D. (2000). Drum-boiler dynamics. Automatica, 36(3): 363-378.

https://doi.org/10.1016/S0005-1098(99)00171-5

\section{NOMENCLATURE}

$\Delta p \quad$ Driving force, $\mathrm{kg} / \mathrm{cm}^{2}$ $g \quad$ Acceleration due gravity, $\mathrm{m} / \mathrm{s}^{2}$

$H$ Height of riser and downcomer column, m

$k \quad$ Dynamic coefficient

$Q \quad$ Rate of heat transfer, W

$\Delta P \quad$ Pressure drop in circulation circuit, $\mathrm{kg} / \mathrm{cm}^{2}$

$X_{t t} \quad$ Martinelli parameter

$\varnothing \quad$ Two-phase multiplier

$q \quad$ Flow, $\mathrm{kg} / \mathrm{s}$

$D \quad$ Diameter of downcomer, $\mathrm{m}$

$x \quad$ Quality of mixture

$V \quad$ Velocity, $\mathrm{m} / \mathrm{s}$

$L \quad$ Length of downcomer,m

$f \quad$ Frictional factor

$v \quad$ Specific volume $\left(\mathrm{m}^{3} / \mathrm{kg}\right)$

$\Delta p_{r f} \quad$ Frictional pressure drop of riser

$\Delta p_{r d} \quad$ Dynamic pressure drop of riser

$h_{f g} \quad$ Latent heat of evaporation, $\mathrm{J} / \mathrm{kg}$

$\Delta p_{d f} \quad$ Frictional pressure drop of downcomer

$\Delta p_{d d} \quad$ Dynamic pressure drop of downcomer

\section{Greek symbols}

\section{$\alpha \quad$ Void fraction \\ $\rho \quad$ Density, $\mathrm{kg} / \mathrm{m}^{3}$ \\ $\mu \quad$ Viscosity, $\mathrm{kg} / \mathrm{s}-\mathrm{m}$}

\section{Subscripts}

$\begin{array}{ll}l & \text { Liquid } \\ v & \text { Vapour } \\ s & \text { Steam } \\ d & \text { Downcomer } \\ r & \text { Riser }\end{array}$

